\title{
The Role of Adverse Life Style Factors in the Cause of Colorectal Carcinoma in the Residents of Yazd, Iran
}

\author{
Mohammad Hassan Lotfi, ${ }^{1}$ Naeimeh Keyghobadi, ${ }^{2,}$ Nasimeh Javahernia, ${ }^{3}$ Soheila Bazm, ${ }^{4}$ Arefeh \\ Dehghani Tafti, ${ }^{3}$ and Hamid Dehghan Tezerjani ${ }^{5}$ \\ ${ }^{1}$ Prevention and Epidemiology of Non-Communicable Disease Research Center, Faculty of Health, Shahid Sadoughi University of Medical Sciences, Yazd, IR Iran \\ ${ }^{2}$ Department of Biostatistics and Epidemiology, Faculty of Health, Shahid Sadoughi University of Medical Sciences, Yazd, IR Iran \\ ${ }^{3}$ Department of Environmental Health, Faculty of Health, Shahid Sadoughi University of Medical Sciences, Yazd, IR Iran \\ ${ }^{4}$ MSc of Medical Library and Information Sciences, Faculty of Health, Shahid Sadoughi University of Medical Sciences, Yazd, IR Iran \\ ${ }^{5}$ Department of Occupational Health, Faculty of Health, Shahid Sadoughi University of Medical Sciences, Yazd, IR Iran \\ "Corespounding author: Naeimeh Keyghobadi, Department of Biostatistics and Epidemiology, Faculty of Health, Shahid Sadoughi University of Medical Sciences, Yazd, IR \\ Iran. E-mail: naeimehkeyghobady@yahoo.com
}

Received 2015 April 5; Accepted 2015 November 22.

\begin{abstract}
Background: This study was designed to investigate the role of lifestyle factors associated with colorectal cancer risk in the population living in Yazd city.

Methods: This case-control study was conducted on 60 patients diagnosed with colorectal cancer and 120 subjects without any sign of colorectal cancer in the city of Yazd. Data was analyzed through SPSS16 and by using Chi-square test and Logistic regression.

Results: The logistic regression model showed that smoking $(\mathrm{OR}=7.79, \mathrm{P}=0.04)$ and History of diabetes $(\mathrm{OR}=7.31, \mathrm{P}=0.04)$ were considered as associated risk factors for colorectal cancer.

Conclusions: The present study showed that smoking and history of diabetes were positively associated with colorectal carcinoma.

Keywords: Colorectal Cancer, Life Style, Case-Control Study
\end{abstract}

\section{Background}

Colorectal cancer is the second leading cause of cancer death in the United Kingdom and the United States [1]. This cancer is the third and fifth common type of cancer in Iranian women and men respectively [2]. Colorectal cancer is a Family history of colorectal cancer increase the risk of colon cancer in which approximately 12 - 15\% of patients those with family members who have colon cancer are at an increase risk of this disease [3]. Dehganzadeh et al. carried out a study and concluded smoking, diabetes and inflammatory bowel disease and living without physical activities are risk factors of colorectal cancer [4]. Physical activity has association with decreased risk of colorectal cancer so that Kruk's review study showed that physical activity places a person at a decreasing risk of colon cancer by 22 percent [5].

\section{Objectives}

Due to this fact that, cancer is the fourth and fifth common form of cancer among the women and men of Yazd [6], respectively and before this research, any analytical study had not been conducted in the province of Yazd, this study has been done to determine the lifestyle factors which increase the risk of colorectal cancer in the people of Yazd.

\section{Methods}

A case-control study was conducted 180 subjects were sampled and divided into two groups: 60 patients who were diagnosed with colorectal cancer in the case group and individuals without any sign of colorectal cancer in the control group. For this study only patients diagnosed with colorectal cancer and who were registered in cancer registry office in Yazd between the years 2011-2012, were entered. Using data from the health center of cancer registry, previous studies and sample size of case-control studies sample size 60 subjects was obtained. Finally, to increase the power of the study, 180 subjects (60 cases and 120 controls) were selected. Cases, all men and women residing in the city of Yazd, who had been histologically confirmed as having colorectal carcinomas and had registered from 2011 - 2012 in a cancer registry center in Yazd. Considering ethi- 
cal aspect in research, pregnant women and patients at the developing stage of colorectal cancer were excluded.

The samples of the control group were selected among neighbors. Each patient with colorectal cancer was matched with two patients in the control group by age $( \pm 2$ years), sex and place of residence. The study was approved by the Medical Ethics Committee of Shahid Sadoughi University of Medical Sciences and Health Services of Yazd and all individuals signed informed consent forms. The data were collected through researcher-made questionnaire, medical records of patients and the interview. The questionnaire consist of questions on demographic information, behavioral information before being diagnosed with colorectal were also considered, as well as, informationrelated to colorectal cancer. In this study, physical activity is an activity of moderate intensity for 30 minutes or more at least four times a week that increases heart rate or breathing level [7]. Statistic of significance was determined at $P$ value $<0.05$. SPSS statistical software, version 16 was used for analysis Forward method in logistic regression and chi-square test was used. Also logistic regression used to eliminate the effect of possible confounding variables.

\section{Results}

In both individual in the cases and control groups 48.3 and 51.7 of the subjects were male and female respectively. The mean age of the subjects in the case and control groups was respectively $58.4 \pm 16.4$ and $58.3 \pm 16.4$ years. Table 1 shows the relationship between smoking, physical activity, medical history and colorectal cancer in the two groups of case and control. A significant association was found between the smoking and physical activity with colorectal cancer.

It means that the amount of smoking and physical inactivity in case group was higher than that of control group. In addition, there were not significant differences between the case and control groups in two variables of using hookah and consumption of opium.

It wasn't found any significant association between the stomach cancer, uterine cancer, inflammatory bowel disease and diabetes with colorectal cancer. So that history of stomach cancer, uterine cancer, inflammatory bowel disease and diabetes were higher in the subjects of the case group than the one in the control group. Also history of colorectal cancer in the first and second-degree relatives was significantly higher in the cases than controls. But history of hypertension was similar in the two groups and any significant differences was observed between the subjects in the case and control groups ( $\mathrm{P}>0.05)$.
Table 2 shows the results of logistic regression analysis. To find the predictive factors of colorectal cancer, 20 variables which were significant at $\alpha \leq 0.2$ in univariate analyses, were entered into the logistic regression model. Finally, variables related to lifestyle, diabetes and smoking variables remained in the model. According to the results of logistic regression, history of diabetes and smoking were two significant predictors of colorectal cancer; therefore it could be conducted that the history of diabetes and smoking increased the risk of colorectal cancer by 7.13 and 7.97 times, respectively.

\section{Discussion}

This study was conducted to investigate the relationship between lifestyle factors and colorectal cancer in the men and women with colorectal cancer in the city of Yazd. Results of univariate analysis showed a significant association between the family history of colorectal cancer in the first-degree relatives and second-degree relatives with colorectal cancer. The Family history of colorectal cancer did not remain in the logistic regression model with the presence of other variables. Dehganzadeh et al. [4] and Safaei et al. [3] did the research and the results showed that the family history of colorectal cancer in first-degree relatives increased the risk of colorectal cancer 35.4 and 2 times, respectively. Our study showed a significant association between smoking and colorectal cancer and the results of the regression model showed that smoking increases the risk of developing colorectal cancer by 7.79 times. He et al. showed in their study the odd ratio of effecting with colorectal cancer is 1.32 in smokers [8]. The results of our study showed that there was not any significant association between the consumption of hookah and opium with colorectal cancer and this is constant with the results of Moshfeghi et al. [9] and Kim et al. studies [10]. Many individuals with addictive behavior don't report taking drugs and hide it therefore, it is estimated that the consumption of opium is more than it is reported. It was believed that physical activity reduces the risk of colorectal cancer by increasing bowel peristalsis that reduces the duration of the exposure of food pathogens to the intestinal wall [11]. Results of univariate analysis showed a significant protective association between physical activity and colorectal cancer that is consistent with Lee et al. [12] and Dehganzadeh et al.'s study [4]. Most of the time in women, colorectal cancer occurs along with ovarian and endometrial cancers. The findings of Park's study showed that in patients with colon cancer, the risk of uterine cancer and ovarian cancer, increases by $43 \%$ and 9 - 19\% increase, respectively [13]. Our result showed a significant relationship between 
Table 1. Association Between Smoking, Physical Activity, Medical History and Colorectal Cancer in the Case and Control Groups

\begin{tabular}{|c|c|c|c|c|}
\hline Variable & Case Group & Control Group & OR(CI\%95) & P Value \\
\hline \multicolumn{5}{|l|}{ Smoking } \\
\hline No & $42(70)$ & $105(87.5)$ & 1 & \\
\hline Yes & $18(30)$ & $15(12.5)$ & $3(1.38-6.49)$ & 0.004 \\
\hline \multicolumn{5}{|c|}{ Using hookah } \\
\hline No & $54(90)$ & $116(96.7)$ & 1 & \\
\hline Yes & $6(10)$ & $4(3.3)$ & $3.22(0.87-11.89)$ & 0.06 \\
\hline \multicolumn{5}{|c|}{ Consumption opium } \\
\hline No & $58(96.7)$ & $119(99.2)$ & 1 & \\
\hline Yes & $2(3.3)$ & $1(8)$ & $4.10(0.36-46.18)$ & 0.25 \\
\hline \multicolumn{5}{|c|}{ Physical activity } \\
\hline No & $49(81.7)$ & $76(63.3)$ & 1 & \\
\hline Yes & $11(18.3)$ & $44(36.7)$ & $0.38(0.18-0.82)$ & 0.01 \\
\hline \multicolumn{5}{|c|}{ History of stomach cancer } \\
\hline No & $57(95)$ & 120 & 1 & \\
\hline Yes & $3(5)$ & 0 & $5.36(1-28.51)$ & 0.03 \\
\hline \multicolumn{5}{|c|}{ History of cervical cancer } \\
\hline No & $56(93.3)$ & 120 & 1 & \\
\hline Yes & $4(6.7)$ & 0 & $5.15(1.28-20.69)$ & 0.01 \\
\hline \multicolumn{5}{|c|}{ History of inflammatory bowel disease } \\
\hline No & $53(88.3)$ & $119(99.2)$ & 1 & \\
\hline Yes & $7(11.7)$ & $1(8)$ & $18.71(1.88-1.30)$ & 0.002 \\
\hline \multicolumn{5}{|c|}{ History of diabetes } \\
\hline No & $35(58.3)$ & $91(75.8)$ & 1 & \\
\hline Yes & $25(41.7)$ & $29(24.2)$ & $2.24(1.15-4.34)$ & 0.01 \\
\hline \multicolumn{5}{|c|}{ History of hypertension } \\
\hline No & $40(66.7)$ & $65(54.2)$ & 1 & \\
\hline Yes & $20(33.3)$ & $55(45.8)$ & $0.59(0.31-1.12)$ & 0.1 \\
\hline \multicolumn{5}{|c|}{ Family history of colorectal cancer in( first-degree) } \\
\hline No & $35(58.3)$ & $113(94.2)$ & 1 & \\
\hline Yes & $25(41.7)$ & $7(5.8)$ & $11.53(4.59-28.93)$ & 0.001 \\
\hline \multicolumn{5}{|c|}{ Family history of colorectal cancer in (second degree) } \\
\hline No & $53(88.3)$ & $116(96.7)$ & 1 & \\
\hline Yes & $7(117)$ & $4(3.3)$ & $3.83(1.07-13.64)$ & 0.02 \\
\hline
\end{tabular}

a history of uterine cancer and gastric cancer among subjects in the case and control groups therefore, the history of uterine and gastric cancer was significantly higher in the people of the case group than the control group. However, in none of the subjects history of ovarian cancer was observed. It was confirmed that Crohn's disease and ulcerative colitis are inflammatory bowel diseases which are effective in the cause of colorectal cancer. Results of univariate analysis showed that inflammatory bowel disease increased the risk of colorectal cancer that is consistent with the previous studies $[4,14]$. Our study showed a significant association between diabetes and colorectal cancer and the results of the regression model showed that diabetes increases the risk of colorectal cancer up to 7.31. The 
Table 2. Effect of Multiple Risk Factors, Modeled with Logistic Regression

\begin{tabular}{cccc}
\hline Independent Variables & B Coefficient & OR $(\mathbf{9 5} \%$ CI $)$ & P Value \\
\hline Smoking & & & \\
No & - & - & \\
Yes & 2.05 & $7.79(1.01-6)$ & 0.04 \\
\hline History of diabetes & & & \\
\hline No & - & - & \\
\hline Yes & 1.98 & $7.31(1.06-50.40)$ & 0.04 \\
\hline
\end{tabular}

results of the meta-analysis study conducted by Larsson et al. showed that diabetic patients have a 30\% increased risk of developing colon cancer compared to non-diabetic patients that is consistent with our findings in this study [15]. In this study, samples were taken from alive people and those who were accessible. The ones who demised and migrated were excluded from the study.Also, due to the ethical issues and the high cost of diagnosing of colorectal cancer, the absence of colorectal cancer in the control group, was based on the self-report of individuals. Therefore there might have been an error in this study. The results of our study showed that smoking and diabetes can significantly increase the risk of colorectal cancer. With the changes in behavioral habits, such as giving up smoking and prevention or treatment of diabetes, the rate of occurrence of colorectal cancer will reduce. In general, it is suggested to reach more accurate results, performed studies with a prospective design and larger sample size.

\section{Acknowledgments}

This study was supported by faculty of health, Shahid Sadoughi University of Medical Sciences. Code Theses: 3029.

\section{Footnotes}

Authors' Contribution: Mohammad Hassan Lotfi, Naeimeh Keyghobadi, Nasimeh Javahernia, Soheila Bazm, Arefeh Dehghani Tafti , Hamid Dehghan Tezerjani had equal role in design, work, statistical analysis and manuscript writing.

Conflict of Interest: The authors declare no conflict of interest.

Funding/Support: Shahid Sadoughi University of Medical Sciences, Yazd, IR Iran.

\section{References}

1. Keyghobadi N, Lotfi MH, Fallahzadeh H, Akhondi M. Nutritional fac tors related to colorectal cancer in the residents of Yazd city [in Persian]. J Health Dev. 2013;2(3):171-81.

2. Hoseini S, Moaddabshoar L, Hemati S, Mohammadianpanah M. An Overview of Clinical and Pathological Characteristics and Survival Rate of Colorectal Cancer in Iran. Ann Colorectal Res. 2014;2(1):17264. doi: 10.17795/acr-17264.

3. Safaee A, Moghimi-Dehkordi B, Pourhoseingholi MA, Vahedi M, Maserat E, Ghiasi S, et al. Risk of colorectal cancer in relatives: a case control study. Indian J Cancer. 2010;47(1):27-30. doi:10.4103/0019509X.58855. [PubMed: 20071786].

4. Dehganzadeh S, Jafaraghai F, Tabari Khomeiran R. Relationship between demographic characteristics, lifestyle, and exposure to stressor events and colorectal cancer [in Persian].JNurs Res (IJNR). 2012;7:615.

5. Kruk J. Physical activity in the prevention of the most frequent chronic diseases: an analysis of the recent evidence. Asian Pac J Cancer Prev. 2007;8(3):325-38. [PubMed:18159963].

6. Eatemed K, Gooya MM, Ramazani R, et al. Iranian Annual of National Cancer Registration Report 2008. Tehran, Iran: Ministry of Health and Medical Education, Center for Disease Control and Prevention; 2008.

7. Agha Molaei T, Tavafian S, Hasani L. Exercise self-efficacy, exercise perceived benefits and barriers among students in Hormozgan University of Medical Sciences [in Persian]. Iran J Epidemiol. 2008;4:9-15.

8. He J, Stram DO, Kolonel LN, Henderson BE, Le Marchand L, Haiman CA The association of diabetes with colorectal cancer risk: the Multiethnic Cohort. Br J Cancer. 2010;103(1):120-6. doi: 10.1038/sj.bjc.6605721. [PubMed: 20531412].

9. Moshfeghi K, Mohammad-Beigi A, Hamedi-Sanani D, Bahrami M. Evaluation the role of nutritional and individual factors in colorectal cancer [in Persian]. Zahedan J Res Med Sci. 2011;13(4):12-7.

10. Kim KS, Moon HJ, Choi CH, Baek EK, Lee SY, Cha BK, et al. The Frequency and Risk Factors of Colorectal Adenoma in Health-Check-up Subjects in South Korea: Relationship to Abdominal Obesity and Age. Gut Liver. 2010;4(1):36-42. doi: 10.5009/gnl.2010.4.1.36. [PubMed: 20479911].

11. Le Marchand L, Wilkens LR, Kolonel LN, Hankin JH, Lyu LC. Associations of sedentary lifestyle, obesity, smoking, alcohol use, and diabetes with the risk of colorectal cancer. Cancer Res. 1997;57(21):478794. [PubMed: 9354440].

12. Lee KJ, Inoue M, Otani T, Iwasaki M, Sasazuki S, Tsugane S, et al Physical activity and risk of colorectal cancer in Japanese men and women: the Japan Public Health Center-based prospective study. Cancer Causes Control. 2007;18(2):199-209. doi: 10.1007/s10552-006-00983. [PubMed: 17206529].

13. Park SY, Kim HS, Yoon KW, Cho SB, Lee WS, Park CH, et al. [Prevalence of colorectal adenoma is increased in patients with gastric adenoma]. Korean J Gastroenterol. 2009;54(4):220-6. [PubMed:19844141].

14. Jess T, Loftus EVJ, Velayos FS, Harmsen WS, Zinsmeister AR, Smyrk TC, et al. Risk of intestinal cancer in inflammatory bowel disease: a population-based study from olmsted county, Minnesota. Gastroenterology. 2006;130(4):1039-46. doi: 10.1053/j.gastro.2005.12.037. [PubMed: 16618397].

15. Larsson SC, Orsini N, Wolk A. Diabetes mellitus and risk of colorectal cancer: a meta-analysis. J Natl Cancer Inst. 2005;97(22):1679-87. doi: 10.1093/jnci/dji375. [PubMed: 16288121]. 